\title{
Heterogeneity of Debt Policies of WAEMU Countries: Convergence or Disparity of Economies
}

\author{
Ibrahima Diallo \\ Faculty of Economics and Management (FSEG), Bamako University of Social Sciences and Management (USSGB), Bamako, Mali \\ Email: man.diallo@hotmail.com
}

How to cite this paper: Diallo, I. (2020). Heterogeneity of Debt Policies of WAEMU Countries: Convergence or Disparity of Economies. Modern Economy, 11, 501-521. https://doi.org/10.4236/me.2020.112037

Received: January 10, 2020

Accepted: February 22, 2020

Published: February 25, 2020

Copyright $\odot 2020$ by author(s) and Scientific Research Publishing Inc. This work is licensed under the Creative Commons Attribution International License (CC BY 4.0).

http://creativecommons.org/licenses/by/4.0/

\begin{abstract}
The impact of monetary policy on economic activity in integrated currency areas may be affected by factors that are primarily related to the convergence of economic structures and fiscal policies. In economic analysis, convergence is used to characterize the process of reconciling economies with respect to certain macroeconomic variables. This notion could involve both real and nominal convergences. Our methodology is inspired by the work of Diarra (2016) and in keeping with the spirit of multilateral surveillance, which consists of judging the performances of the states with respect to the criteria. A modification was made to the convergence sigma technique. This modification involved estimating the deviation from the norm only if it is not respected. If the standard is respected, we consider that the difference is nil. The analysis of the convergence sigma reveals a heterogeneity of WAEMU country behaviour in the convergence process. This state of affairs is explained by structural differences. Economies react differently when they are affected by asymmetric shocks. Because fiscal policy is the only stabilization instrument, it reflects the divergence of preferences in economic policy. The results show that the disparities in WAEMU economies are related to the asymmetric shocks affecting them and to the structural heterogeneity that results in non-cooperative use of budget instruments.
\end{abstract}

\section{Keywords}

Debt Policies, Convergence, Heterogeneity, WAEMU

\section{Introduction}

The recent debt crisis has created new challenges for currency unions. In a monetary union, countries renounce their national monetary and exchange rate poli- 
cies in favour of increased integration. In the case of large asymmetric shocks and in the absence of transfers through a federal budget, national fiscal policy remains the only tool available for WAEMU states to cushion these shocks, and it is essential for the stability of the Union. Understanding the specificities of indebtedness and the convergence of fiscal shocks in different countries is necessary to ensure the correct conduct of economic policies in a monetary union.

Several factors can affect the impact of monetary policy on economic activity. In integrated currency areas, these factors are mainly related to the convergence of economic structures and fiscal policies. In WAEMU countries, due to differences in economic structures, the effects of monetary action are differentiated by country. Indeed, the impacts of the BCEAO interest rate changes on economic growth are sometimes counterintuitive and contradictory from one country to another.

The analysis of convergence is necessary because it constitutes an essential basis for the search for healthy and sustainable growth and for better global integration of the countries. In addition, the credibility and durability of a currency area depend on the degree of convergence of the economies belonging to the area and the relative symmetry of the shocks that affect it.

Given the growing interest in the convergence of economies, as well as the urgency of the consolidation of the macroeconomic framework of their zone, WAEMU states have established convergence criteria and multilateral surveillance, largely inspired by the Maastricht Treaty (the Convergence of Growth and Solidarity Pact).

Here, we have focused our analysis on nominal convergence as it refers to the convergence criteria established within a monetary union to introduce fiscal discipline. Moreover, our analysis is performed before and after the adoption of fiscal rules and covers a more recent period with updated data, using three criteria (the ratio of the overall fiscal balance to GDP, the ratio of debt to GDP and the ratio of the wage bill to tax revenues). However, this approach makes it possible to assess more effectively whether the degree of non-compliance is reduced over time and if we are getting closer and closer to a zero gap and thus to compliance with the standard.

By adopting the sigma convergence technique and considering all eight WAEMU countries, convergence is generally evaluated on the basis of the sum of the squares of the national differences and the average value. This choice is justified by the fact that the average value is unweighted, that is calculated arithmetically. It is enough that some countries representing only a low weight in the union and have high rates to move the average. This can lead to a convergence bias with respect to reality.

We can define economic convergence as the reduction of the gaps between sets of economic indicators relating to several countries. Based on the economics literature, we distinguish five concepts of convergence: absolute, conditional, beta, sigma as well as convergence clubs. 


\section{Foundations of Convergence of Economies}

The analysis of the process of convergence of economies has been the subject of several works over many decades. According to the traditional theory of growth, similar economies (in terms of technology and preference) will converge towards the same level of GDP per capita. On the other hand, beginning with Romer (1986), the theory of endogenous growth predicts that the differences between per capita GDP levels will persist.

Faced with this theoretical debate, several attempts have emerged to test the implications of these two types of model. A number of hypotheses have been developed to verify economic convergence, including absolute, conditional and convergence clubs.

\section{From the Questioning of the Absolute Convergence Hypothesis ... to the Robustness of the Conditional Convergence Hypothesis?}

Today's debate is based on the notion of absolute convergence, which states that, in the long run, despite initial conditions, per capita incomes or per capita will converge towards one another. Nevertheless, given the importance of the role of structural characteristics of countries in determining the long-term economic equilibrium, the hypothesis of absolute convergence was rapidly rejected by econometric regressions based on cross-sectional data (1991) and the evolution of income distribution between countries (Quah, 1996) ${ }^{1}$. Some authors such as Barro (1991), Mankiw, Romer and Weil (1992) and Barro and Martin (1995) have shown that the neoclassical growth model advocates conditional rather than absolute convergence; hence, the rejection of the absolute convergence hypothesis does not necessarily lead to the rejection of the neoclassical growth model per se.

According to the conditional convergence hypothesis, the rate of economic growth is a decreasing function of the level of production per capita among all the similar countries in terms of preferences, technologies, population growth, public policies, etc. Countries that are similar in all respects, except for their initial level of per capita income, are presumed to converge towards the same stationary state; in other words, they converge towards each other.

In such a scenario, a temporary shock can alter international rankings in the short term, but will have no lasting effect in the long run. In other words, this notion of conditional convergence is closely linked to the idea that each economy is characterized by a single, globally stable, stationary equilibrium. It follows that states that are similar in terms of a dynamic system, that is to say in their "fundamentals", converge towards each other despite their initial conditions.

Moreover, it is clear that if the dynamic system is characterized by the existence of multiple and locally stable equilibria, the hypothesis of convergence

${ }^{1}$ Convergence within a subset of countries selected on the basis of proximity to their initial or terminal conditions (Baumol, 1986) is not empirical evidence of the absolute convergence hypothesis, but rather evidence of the hypothesis of club or conditional convergence forms (De Long, 1988). 
clubs would be preferable to that of conditional convergence. Countries that are identical in their structural characteristics converge to an identical long-term equilibrium if, and only if, their initial per capita production levels are too far apart. In such a case, a temporary shock can affect the economy in a sustainable manner.

The evaluation of the two hypotheses thus amounts to examining the plausibility of the existence of a single, globally stable long-term equilibrium rather than the existence of multiple equilibria that are locally stable.

Under the traditional neoclassical specification of Galor (1996), it has been shown that the conditional convergence hypothesis appears as the only testable implication arising on the one hand from the growth model (Solow, 1956) and on the other hand from the optimal growth model (Ramsey, 1928). Hence, the economy is characterized by a unique stationary equilibrium and a decrease in the rate of growth as the economy approaches its long-term solution.

On the other hand, in the model of nested generations, if one does not impose other restrictions on preferences and on technology than those in the neoclassical model, then the hypothesis of convergence of clubs becomes more relevant than that of conditional convergence. Galor's basic argument (Galor, 1996) is that it is generally accepted that conditional convergence is linked to the assumption of decreasing marginal returns in the production function.

\section{Convergence Concepts}

We retain five concepts of convergence that we find in the economics literature. All of these approaches ultimately seek to assess whether living standards in developing economies tend to approach developed country standards over time.

\section{Absolute and Conditional Convergences}

To understand absolute convergence, we test the following hypothesis: did the initially poor economies have higher per capita growth rates than the initially rich economies? If this hypothesis is true, there is "absolute convergence".

Conditional convergence can be defined as the convergence of each economy towards its own path of equilibrium. In other words, a country has a higher growth rate per capita than it is far from its long-term equilibrium path. Even if it is not directly a question of convergence between countries, there is implicitly absolute convergence if the countries have the same path of long-term equilibrium.

\section{Beta and Sigma Convergences}

According to Barro and Martin (1992), $\beta$-convergence applies if the initially poor country grows faster than the initially rich country, so that per capita income converges (absolute convergence). The coefficient $\beta$ is, in this case, positive and measures the speed of absolute convergence.

For these same authors, $\sigma$-convergence occurs if the dispersion of per capita 
income of a group of countries (represented by the coefficient $\sigma$ ) decreases with time. In other words, convergence occurs when the GDP per capita converges towards the average value of the sample.

\section{Convergence Clubs}

The approach of convergence clubs allows us to consider catch-up phenomena limited to certain groups of countries. In other words, when some economies have the same structural characteristics, they can converge if their initial conditions are similar. In this respect, the most telling example of a convergence club is that of emerging countries. Indeed, emergence would thus constitute a transition and an intermediary step between divergence and convergence with rich countries.

\section{Reminder of Convergence Criteria in WAEMU Zone}

In the WAEMU zone, we distinguish between the old 1999 convergence criteria and the new 2015 criteria.

\section{The Old Convergence Criteria of $\mathbf{1 9 9 9}$}

The organization of convergence, stability, growth and solidarity is based on a rigorous monitoring of a set of convergence indicators affecting the real sector, the balance of payments, public finances and the currency.

The convergence criteria are the performance indicators for assessing the degree of achievement of the Convergence, Stability, Growth and Solidarity Objectives as set out in Title II of the Supplementary Act $\mathrm{N}^{\circ} 04 / 99$ on the Convergence Pact: stability, growth and solidarity among the WAEMU states. They consist of first- and second-rank criteria.

\section{Criteria of the First Rank}

The primary criteria are those for which non-compliance leads to the explicit formulation of directives by the Council asking the Member State concerned to develop and implement a program of corrective measures. There are four (4) first-ranking criteria:

1) Ratio of the basic fiscal balance ${ }^{2}$ to the nominal GDP (key criterion ${ }^{3}$ ): should be greater than or equal to $0 \%$ in the year 2002;

2) Average annual inflation rate: should be maintained at a maximum of $3 \%$ per year;

3) Ratio of outstanding domestic and external debt to nominal GDP: should not exceed $70 \%$ in 2002;

\section{4) Arrears of payment:}

\footnotetext{
${ }^{2}$ Basic budget balance $=$ Total revenue (excluding grants) - Current expenditure - Public investment expenditure financed from internal resources.

${ }^{3}$ The criterion of the basic fiscal balance to nominal GDP, the non-compliance of which is likely to trigger the sanctions mechanism.
} 
- Domestic payment arrears: no accumulation of arrears on the management of the current period;

- External payment arrears: no accumulation of arrears on the management of the current period.

\section{Second-Rank Criteria}

The second-tier criteria are treated as indicative structural benchmarks that are rigorously monitored due to the critical role they play in achieving the objective of internal and external sustainability of economies. Their non-compliance, however, is not the subject of explicit recommendations for the implementation of a program of corrective measures.

They can be used in the formulation of economic policy recommendations to ensure compliance with the first-rank criteria. The second-rank criteria, four (4) in number, are as follows:

1) Ratio of the wage bill to tax revenues: should not exceed $35 \%$ in the year 2002

2) Ratio of public investments financed by internal resources to tax revenues: should reach at least $20 \%$ in the year 2002

3) Ratio of the current external deficit excluding grants to nominal GDP: should not exceed $5 \%$ in the year 2002

4) Tax pressure rate ${ }^{4}$ : should be greater than or equal to $17 \%$ in the year 2002

In 2006, two complementary indicators (underlying inflation and corrected budget balance) were adopted by the WAEMU Council of Ministers. The adjusted basic balance is calculated by adding to total receipts (excluding grants) the amount of foreign budgetary donations and the amount of HIPC assistance that financed current expenditures and public investment expenditures.

Compliance with the main criterion of fiscal convergence remains limited, suggesting a need to review the regional surveillance framework. Five out of eight countries did not meet the basic fiscal balance criterion in 2012, and it is likely that this criterion will not be observed in 2013 either by the two largest economies (Côte d'Ivoire and Senegal).

This criterion has rarely been respected by the majority of member countries, which calls into question its relevance and credibility. After debt relief, the debt criterion is now respected by all countries (IMF, 2013).

\section{New 2015 Convergence Criteria}

Faced with many difficulties, the question arose as to whether the criteria of the 1999 pact were still appropriate. In this regard, the WAEMU Commission commissioned a study on debt dynamics and a review of convergence criteria to examine the entire scheme. The conclusions and recommendations made by this study led to the adoption in 2015 of Additional Act N 01/2015/CCEG/WAEMU ${ }^{4}$ Tax pressure rate $=$ Tax revenue on nominal GDP. 
establishing new convergence criteria. These criteria are five (5): three (3) firstand two (2) second-ranking criteria.

\subsection{First-Rank Criteria}

The three (3) new first-rank convergence criteria are:

\subsection{Ratio of the Overall Fiscal Balance, Including Grants, to Nominal GDP (Key Criterion): Must Be Greater Than or Equal to $-3 \%$ in 2019}

This ratio is the new key criterion for the convergence of the Union. This is the most commonly used indicator for assessing a state's budget position. It has the advantage of making it possible to provide an overall assessment of the state budget and helps to assess the need for state debt.

In addition, it is the criterion adopted by several regional economic communities, particularly within the European Union and the Economic Community of West African States (ECOWAS). However, this criterion has a significantly more accounting-oriented nature. In its place, one might think to apply the golden rule of public finances by taking the current structural balance excluding public investments that must be balanced. In this respect, we only go into debt to invest, and we will thus have a reading that is less accounting and more economical of this criterion.

\subsection{Average Annual Inflation Rate: Should Be 3\% Maximum, per Year}

The analysis of the tables on the state of convergence for the period 2000-2012 in the Union shows that the average annual inflation rate was generally in line with the community standard of 3\% in most Member States. State.

According to Diarra (2014), the achievement of this criterion by most countries must be put into perspective, in that the inflation observed in the WAEMU countries is largely imported and often depends on exogenous shocks. According to a study by IMF Gupta, Powell and Yang (2005), it was concluded that an inflation rate below $5 \%$ in WAEMU countries is not conducive to growth.

\subsection{Ratio of Outstanding Domestic and External Debt to Nominal GDP: Should Not Exceed 70\% in 2019}

This criterion has been renewed, but gives rise to substantial debate around the $70 \%$ standard. This rate is considered high for some partners and many observers because compliance with this criterion would not be facilitated without taking into account the debt relief provided under HIPC initiatives.

However, according to the reports of the WAEMU commission (UEMOA, 2017; UEMOA, 2016), all the states have managed to respect the debt stock criterion in 2013, 2014 and 2015. In 2016, Togo is the only Member State that has not complied with the criterion on the debt ratio (see Table 1). Outstanding total public debt relative to nominal GDP Payroll on tax revenues. 
Table 1. State of convergence of WAEMU countries.

\begin{tabular}{|c|c|c|c|c|c|c|c|c|c|c|c|c|c|}
\hline & & \multicolumn{8}{|c|}{$\begin{array}{l}\text { State of achievement of } 2016 \text { criteria by country } \\
\text { and performance review 2013, } 2014 \text { and } 2015\end{array}$} & \multicolumn{4}{|c|}{$\begin{array}{l}\text { Number of countries } \\
\text { that met the criterion }\end{array}$} \\
\hline & & BEN & BFA & CIV & GNB & MLI & NER & SEN & TGO & 2016 & 2015 & 2014 & 2013 \\
\hline 1 & $\begin{array}{l}\text { Overall budget balance, } \\
\text { including grants, on nominal GDP } \\
\text { (standard } \geq-3 \%)\end{array}$ & -6.2 & -3.1 & -4.1 & -4.0 & -3.9 & -6.1 & -4.2 & -8.5 & 0 & 3 & 3 & 4 \\
\hline 2 & $\begin{array}{l}\text { Average annual inflation rate } \\
\quad \text { (standard } \leq 3 \%)\end{array}$ & -0.8 & -0.2 & 0.7 & 1.5 & -1.7 & 0.2 & 2.2 & 0.9 & 8 & 8 & 8 & 8 \\
\hline 3 & $\begin{array}{l}\text { Outstanding total public debt to } \\
\text { nominal GDP (standard } \leq 70 \% \text { ) }\end{array}$ & 49.4 & 34.2 & 42.1 & 47.5 & 30.3 & 39.7 & 62.3 & 75.5 & 7 & 8 & 8 & 8 \\
\hline 4 & $\begin{array}{l}\text { Payroll on tax revenues } \\
\quad \text { (standard } \leq 35 \%)\end{array}$ & 55.2 & 51.6 & 41.8 & 46.0 & 32.1 & 43.7 & 32.0 & 32.1 & 3 & 3 & 3 & 3 \\
\hline \multirow[t]{5}{*}{5} & Tax pressure rate (standard $\geq 20 \%$ ) & 12.6 & 15.0 & 15.6 & 10.0 & 14.9 & 13.6 & 20.6 & 22.1 & 2 & 1 & 1 & 1 \\
\hline & 2016 & 2 & 2 & 2 & 2 & 3 & 2 & 4 & 3 & & & & \\
\hline & 2015 & 2 & 3 & 3 & 2 & 4 & 2 & 3 & 4 & & & & \\
\hline & 2014 & 3 & 3 & 3 & 2 & 2 & 3 & 3 & 4 & & & & \\
\hline & 2013 & 3 & 2 & 3 & 2 & 3 & 4 & 3 & 4 & & & & \\
\hline
\end{tabular}

Source: Author.

\section{Second-Rank Criteria}

Since 2015, there have been two (2) new second-tier convergence criteria for WAEMU countries:

\subsection{Ratio of the Wage Bill to Tax Revenues: Must Not Exceed $35 \%$ in 2019}

The ratio of payroll to tax revenue is an indicative structural benchmark and could be used in the formulation of economic policy recommendations to ensure compliance with the first-rank criteria.

\subsection{Tax Rate: Must Be Greater Than or Equal to 20\% in 2019}

This criterion has been renewed, but its rate has been revised upwards: instead of $17 \%$, this rate increases to $20 \%$. It is important to note that this rate should be limited to tax revenues excluding revenues related to oil and mining.

\section{Review of Empirical Studies on the State of Convergence of WAEMU Countries}

Nearly two decades after the beginning of the convergence process, many economists have taken stock of economic integration given the monetary integration already achieved. However, empirical studies carried out on WAEMU states to assess the symmetry and convergence of macroeconomic policies can be divided into two main groups.

One group includes studies explicitly oriented towards the analysis of nominal 
and/or real convergence of economies, such as Dore and Masson (2002), Wane (2004), Bamba (2004), Boogardes and Tsangarides (2005), Guillaumont and Tapsoba (2009); whereas the second group features studies particularly dedicated to the dynamic analysis of the symmetry and convergence of macroeconomic shocks (Ngoma, 2000; Houssa, 2006).

In the first category, different empirical methods are used to analyse the convergence of economies. The literature provides several approaches to take into account different patterns of convergence and study. The panel analyses were tested by convergence or inversion of stationary states Canova and Marcel (1995), or tested by the stability of the series and their property of return to the average Gaulier, Hurlin and Pierre (1997).

According to Bernard and Durlauf (1991) cointegration analyses convergence as a long-term process. This process can be continuous or evolving. In addition, it makes it possible to distinguish the convergent series from those that converge (to a constant close) and those that diverge.

To detect convergence clubs, convergence can be tested by analysing the evolution of the distribution of series over time (Quah, 1993). According to Sarr and N'diaye (2010), all these different tests above offer a multitude of approaches that can be complementary; their use depends on the types of data available and the concept of convergence adopted.

At first, Wane (2004), using the classical Solow model, concludes that there is no clear indication of a sigma converging per capita income in WAEMU countries over the period 1965-2002. However, his analysis shows that periods of strong divergences between 1965 and 1978 alternate with periods of strong convergence between 1979 and 2002. In a second step, the author estimates using dynamic heterogeneous panels a model of Solow-increased human capital.

That study's results show both short- and long-term positive and significant impacts of human capital on the growth of per capita income in WAEMU countries. According to the author, a significant difference from the previous estimates is that per capita income in the area converges to a common steady state.

Absolute convergence is thus accepted, as well as conditional convergence. Its study shows that the speed of adjustment is $6 \%$ and can rise to $27 \%$ when the investment profile is harmonized (conditional convergence). Wane concludes that this speed of adjustment hides a significant disparity: it ranges from $2 \%$ for Burkina Faso to $71 \%$ for Togo.

The study of Boogardes and Tsangaries (2005) used an indicator that they termed the average disparity. According to these authors, such disparity is an indicator that estimates the weighted standard deviation of the variable $X$ of country $i$ at each point of time to the Union average over the period 1990-2003. Let $X_{i t}$ be the observed value of the variable $X$ of country $i$ during year $t$, and Pit the weight of country $i$ in year $t$ for the observed variable; the average disparity is written as:

$$
\left[\sum_{i=1}^{7} P_{i t}\left(X_{i t}-\bar{X}_{t}\right)^{2}\right]^{1 / 2}
$$


During their investigation, Boogardes and Tsangarides (2005) show that a low (high) value of this indicator indicates a tendency towards convergence (divergence). They reach the same conclusions as Wane (2004) and find that neither the variables ${ }^{5}$ representing the sources of growth nor those representing the criteria imposed by the Area converge. In particular, low-income countries have not seen their relative income increase, indicating the absence of a gravity pool in the WAEMU zone.

The absence of convergence sigma suggests that the accumulation of traditional factors of production (capital and labour) is not sufficient to explain growth differences in the Area and increases the likelihood that an endogenous growth process is at stake ${ }^{6}$. This can also be explained by country-specific variables such as human capital accumulation, or other economic policy variables, as well as changes in total factor productivity (development aid, government expenditures, credit to the private sector, degree of openness to the outside world).

Bamba (2004) conducted a convergence study more focused on the criteria of the Pact. Its methodology is based on the Kalman filter and resumes the tests proposed by Haldane and Hall (1991) in an attempt to capture the dynamics of the nominal convergence process. It concludes that the rate of tax burden and the external deficit of all the States of the Union, with the exception of Senegal, is converging, and that the inflation rate of all the countries in the zone over the period 1980-2001 to the Community standard of 3\%.

However, it denotes phases of divergence and convergence in terms of countries' budget balances. These are related to the asymmetric shocks affecting them, and to their structural heterogeneity that seems to result in non-cooperative use of budget instruments. For other fiscal variables, the degrees and dynamics of convergence vary.

Overall, there is a heterogeneity of state behaviour in the convergence process. This state of affairs can be explained by structural differences. Economies react differently when they are affected by asymmetric shocks. Because fiscal policy is the only stabilizing instrument, it reflects the divergence of preferences in economic policy.

The study by Dore and Masson (2002) relies on the calculation of the structural balance likely to take into account international environment shocks to demonstrate the lack of convergence of the WAEMU economies, due among other things to the deterioration of the terms of trade and unfavourable movements of the business cycle. Houssa's (2006) analysis estimates a dynamic factor ${ }^{5}$ This indicator has been calculated for real GDP, savings-to-GDP ratios, investment in GDP; the overall balance, the primary balance, tax revenue, total public expenditure, salary expenditure and public investment expenditure.

${ }^{6}$ Solow's classical model and its augmented version predict that each economy converges to its per capita income level in the steady state. The existence of a steady-state equilibrium level of per capita income depends heavily on the assumptions of diminishing returns of capital and labour. When these assumptions are relaxed, the per capita income level in the steady state is undefined, and differences between countries may persist indefinitely even if the countries have a similar rate of capital accumulation and population growth. The relaxation of this hypothesis is the main innovation of the endogenous growth theory (Lucas, 1988). 
model to infer a negative and weak correlation of supply shocks and a symmetry of demand shocks. Its results show that the transmission of supply shocks at the national level is generally asymmetrical, which reflects the presence of structural heterogeneity between WAEMU member countries.

In addition, in a comparative study of the determinants and performances of economic integration in the monetary unions of the franc zone (WAEMU and CEMAC), Ndiaye (2007) concludes that member countries of both unions are unaware of the expected efficiencies of economic and monetary integration. Convergence tests of economic policies and structures using the recursive least squares (RCM) method over the period 1980-2000 show that although some progress has been made for certain convergence criteria, more disparities exist between the different economies of the Member States within each union than between the two Economic and Monetary Unions themselves.

Following the work of Barro and Martin (1992), Ondo and Bercart (1997) found a weak trend in the convergence of long-term per capita GDP levels using ordinary cross-section least squares on countries in the franc zone.

Diarra (2016), in a study on the period 2000-2014, makes a retrospective analysis between the new criteria and the old WAEMU convergence criteria. Focusing mainly on the criterion of budget balance, which is the major change in the new pact, the author shows that the new criterion of budget balance presents a lower requirement for states than the old criterion. By making projections on the new criterion and considering the conditions required to return to the stability phase, he concludes that it will be difficult for the WAEMU countries to converge by 2019.

\section{Analysis of Convergence Sigma in WAEMU Zone}

In economic analysis, convergence is used to characterize the process of reconciling economies with respect to certain macroeconomic variables. This notion could be both real or nominal convergences. Here, we have focused our analysis on nominal convergence for several reasons. It refers to convergence criteria established within a monetary union to establish fiscal discipline.

In the WAEMU zone, the thresholds established for compliance with the criteria are defined by quantified economic objectives set in nominal terms, hence the choice of nominal convergence. This notion refers to the convergence of the nominal values of certain variables such as the budget deficit, the inflation rate and the public debt. Moreover, it draws its foundations from theoretical analyses related to the coordination of monetary and budgetary policies (policy mix). Finally, according to Barthe (2000), the criteria set for nominal convergence are necessary because they bring fiscal policy closer to monetary policy.

The convergence sigma technique has been used by Tanimoune, Combes and Plane (2005), Fouda Owoundi (2009) and Diarra (2016) to analyse the decline in dispersion of convergence criteria in WAEMU countries and in the franc zone.

In contrast to previous work, our work focuses on the nominal convergence of WAEMU countries by analysing data before and after the adoption of fiscal rules 
and covering a more recent period with updated data. The analysis is based on three criteria: the ratio of the overall fiscal balance to GDP, the ratio of debt to GDP and the ratio of the wage bill to tax revenues. The choice of these three indicators is not fortuitous.

The ratio of the overall fiscal balance to GDP (the key criterion of convergence) is the most commonly used indicator for assessing the fiscal position of a state. As such, it has the advantage of allowing an overall assessment of the state budget and helps to assess the state's need for debt.

The ratio of debt to GDP makes it possible to judge the sustainability of the debt policy. The ratio of payroll to tax revenue is an indicative structural benchmark and can be used in the formulation of economic policy recommendations to ensure compliance with the first two criteria.

By adopting the sigma convergence technique and considering all eight WAEMU countries, convergence is generally evaluated on the basis of the sum of the squares of the national differences and the average value. This choice is justified by the fact that the average value is unweighted, that is calculated arithmetically. It is enough that some countries representing only a low weight in the union and have high rates to move the average. This can lead to a convergence bias with respect to reality. However, the use of standards makes it possible to deal with this problem, hence the reference to which the tightening must take place is predetermined.

Building on the work of Diarra (2016) and maintaining the spirit of multilateral surveillance, which consists of judging the performance of states by whether or not they meet the criteria, another modification was made to the convergence sigma technique. This modification consists of estimating the deviation from the norm only if it is not respected. If the standard is respected, we consider the difference to be nil.

However, this approach makes it possible to assess more effectively whether the degree of non-compliance is reduced over time and if we are getting closer and closer to a zero gap and thus to compliance with the standard.

Thus, considering " $X$ " as the criterion of convergence; " $X_{i, t}$ " the value observed for this criterion for year $t$ and in a given country $i$ and " $\bar{X}$ " the standard of the criterion as set by the Stability and Convergence Pact. For all eight States in the WAEMU zone, the formula for the modified convergence sigma is as follows for criterion " $X$ " and for a given year $t$.

$$
\sigma_{t}(X)=\sqrt{\sum_{i=1}^{8} \frac{\left(X_{i, t}-\bar{X}\right)^{2}}{8}}
$$

In view of the methodological approach presented above, we have:

- For the ratio of the overall fiscal balance to GDP (key criterion), where the norm is only respected if the balance is $\geq-3 \%$ :

Ecart $=X_{i, t}-(-3)=0 \quad$ if $\quad X_{i, t} \geq-3 ; \quad$ Ecart $=X_{i, t}-(-3)=b \quad$ (to be determined) if $X_{i, t}<-3$;

- For the ratio of debt to GDP, where the norm is only respected if the ratio of 
debt to GDP is $\leq 70 \%$ :

Ecart $=X_{i, t}-(70)=0 \quad$ if $\quad X_{i, t} \leq 70 ; \quad$ Ecart $=X_{i, t}-(70)=b \quad$ (to be determined) if $X_{i, t}>70$;

- For the ratio of the wage bill to tax revenue, where the norm is only respected if the ratio of the wage bill to tax revenue is $\leq 35 \%$ :

Ecart $=X_{i, t}-(35)=0$ if $X_{i, t} \leq 35 ; \quad$ Ecart $=X_{i, t}-(35)=b \quad$ (to be determined) if $X_{i, t}>35$.

There is convergence between two years $t$ and $t+h$, if $\sigma_{t+h}(X)$ is inferior to $\sigma_{t}(X)$.

\section{Result of Convergence Sigma before the Adoption of Budgetary Rules}

Table 2 presents the results of the sigma convergence of the overall fiscal balance on GDP, the debt-to-GDP ratio and the wage bill on the Tax Revenue before the adoption of the debt rules (1980-1999).

Table 2. Results of the dispersions of convergence sigma WAEMU countries before the adoption of debt rules.

\begin{tabular}{|c|c|c|c|}
\hline Year & Overall fiscal balance/GDP & Debt/GDP ratio & Payroll/Tax revenue \\
\hline 1980 & 0.05 & 0.34 & 0.77 \\
\hline 1981 & 0.05 & 0.32 & 0.77 \\
\hline 1982 & 0.05 & 0.34 & 0.71 \\
\hline 1983 & 0.06 & 0.35 & 0.67 \\
\hline 1984 & 0.05 & 0.37 & 0.64 \\
\hline 1985 & 0.03 & 0.45 & 0.63 \\
\hline 1986 & 0.02 & 0.32 & 0.58 \\
\hline 1987 & 0.03 & 0.35 & 0.59 \\
\hline 1988 & 0.04 & 0.35 & 0.53 \\
\hline 1989 & 0.06 & 0.42 & 0.57 \\
\hline 1990 & 0.04 & 0.46 & 0.35 \\
\hline 1991 & 0.04 & 0.48 & 0.41 \\
\hline 1992 & 0.04 & 0.51 & 0.51 \\
\hline 1993 & 0.05 & 0.56 & 0.48 \\
\hline 1994 & 0.03 & 0.77 & 0.40 \\
\hline 1995 & 0.03 & 0.56 & 0.25 \\
\hline 1996 & 0.04 & 0.51 & 0.17 \\
\hline 1997 & 0.03 & 0.44 & 0.17 \\
\hline 1998 & 0.03 & 0.66 & 0.36 \\
\hline 1999 & 0.02 & 0.57 & 0.18 \\
\hline
\end{tabular}

Source: Author. 
For the criteria of overall budget balance and the wage bill on tax revenue, the analysis of the period before the introduction of the debt rules shows a narrowing of dispersion over time.

As for the ratio of debt to GDP, we do not observe a narrowing of dispersion over time. In order to judge the convergence process during the period before the adoption of the debt rules on the three criteria, we calculated the linear trends of the three series and tested whether the slope of each trend is negative and significantly different from zero (see Table 3 and Annex 1).

The trend observed before the adoption of the debt rules is negative and significantly different from zero for the criteria of overall budget balance and the wage bill on Tax Revenue. On the other hand, for the debt criterion on GDP, it is positive and significantly different from zero.

Therefore, from the analysis of the convergence sigma before the adoption of the debt criteria, a convergence for the criteria of overall budget balance and the wage bill on the Tax Revenue appears, and a lack of convergence for the criterion debt on GDP occurs.

In addition, the analysis of Graph 1 confirms the results obtained for the three criteria.

\section{Results of Convergence Sigma after Adoption of the Rules}

Table 4 shows the results of the sigma convergence of the overall fiscal balance on GDP, the debt-to-GDP ratio and the wage bill on tax revenue after the introduction of the debt rules (2000-2015).

Table 3. Results of the dispersions of convergence sigma WAEMU countries before the adoption debt rules.

\begin{tabular}{cccc}
\hline & $\begin{array}{c}\text { Overall fiscal } \\
\text { balance/GDP }\end{array}$ & Debt/GDP ratio & $\begin{array}{c}\text { Payroll/Tax } \\
\text { revenue }\end{array}$ \\
\hline \multirow{2}{*}{ Sigma } & $-0.0011^{\star * *}$ & $0.0163^{* * *}$ & $-0.0305^{* * *}$ \\
& $(-2.97)$ & $(5.40)$ & $(-11.10)$ \\
\hline
\end{tabular}

Source: Author. $\left({ }^{* *}\right),\left({ }^{* *}\right)$, and $\left(^{*}\right)$ respectively signify significance at the $1 \%, 5 \%$ and $10 \%$.

Overall fiscal balance/GDP

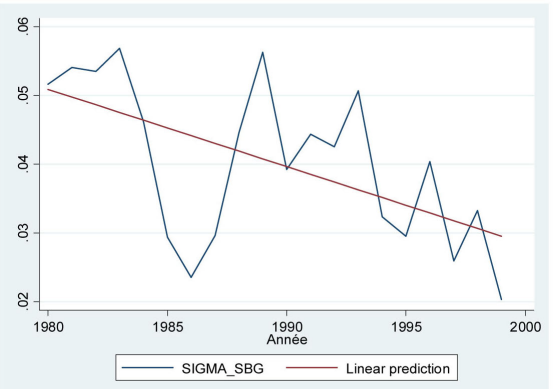

Debt/GDP ratio

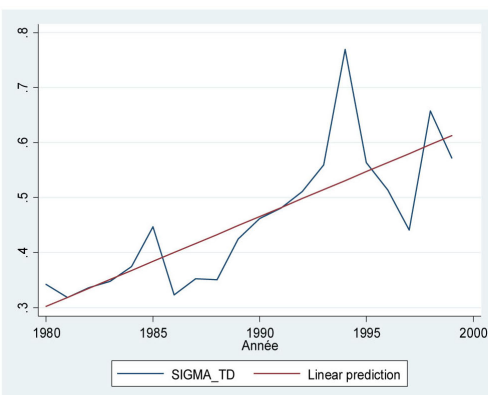

Payroll/Tax revenue

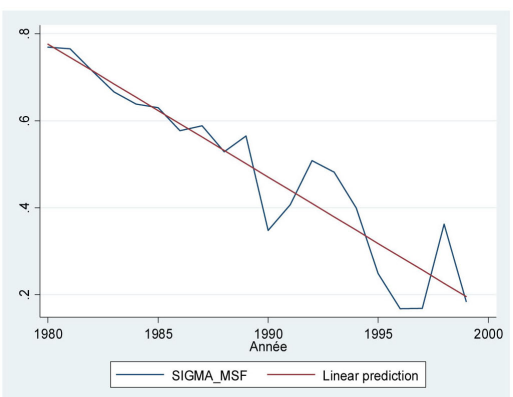

Graph 1. Representation of the dispersions of convergence sigma WAEMU countries before the adoption debt rules. Source: Author. 
Table 4. Results of dispersions of convergence sigma WAEMU countries after the adoption debt rules.

\begin{tabular}{cccc}
\hline Year & Overall fiscal balance/GDP & Debt/GDP ratio & Payroll/Tax revenue \\
\hline 2000 & 0.02 & 0.56 & 0.22 \\
2001 & 0.02 & 0.47 & 0.27 \\
2002 & 0.02 & 0.40 & 0.28 \\
2003 & 0.02 & 0.45 & 0.35 \\
2004 & 0.02 & 0.44 & 0.42 \\
2005 & 0.02 & 0.36 & 0.34 \\
2006 & 0.20 & 0.52 & 0.19 \\
2007 & 0.04 & 0.56 & 0.20 \\
2008 & 0.03 & 0.50 & 0.27 \\
2009 & 0.03 & 0.46 & 0.22 \\
2010 & 0.02 & 0.46 & 0.20 \\
2011 & 0.02 & 0.46 & 0.16 \\
2012 & 0.02 & 0.48 & 0.15 \\
2013 & 0.01 & 0.47 & 0.16 \\
2014 & 0.02 & 0.47 & 0.20 \\
2015 & 0.03 & 0.47 & 0.15 \\
\hline
\end{tabular}

Source: Author.

The figures show a quasi-stagnant trend in the dispersion of the budget balance over GDP with a peak (a strong divergence) in 2006. This strong divergence seems to be explained by the exceptional donations received by Niger in the context of the food crisis in 2006 as noted in Diarra (2016).

As for the ratio of debt to GDP and wage bill to Tax Revenue, we do not see a narrowing of dispersion over time. To judge the convergence process during the period after the adoption of the debt rules on the three criteria, we then calculated the linear trends of the three series and tested whether the slope of each trend is negative and significantly different from zero (see Table 5 and Annex 2).

The trend observed after the adoption of the debt rules is negative and significantly different from zero for the wage bill criterion on Tax Revenue; in addition, it remains negative and insignificant for the overall fiscal balance on GDP. On the other hand, for the debt-to-GDP criterion, it is positive and not significant.

Therefore, from the analysis of the convergence sigma after the introduction of the debt criteria, a convergence for the criterion of the wage bill on Tax Revenue appears and a lack of convergence for the criteria of overall budget balance and the debt on GDP is also apparent.

In addition, the analysis of Graph 2 confirms the results obtained for the three criteria. 
Overall fiscal balance/GDP

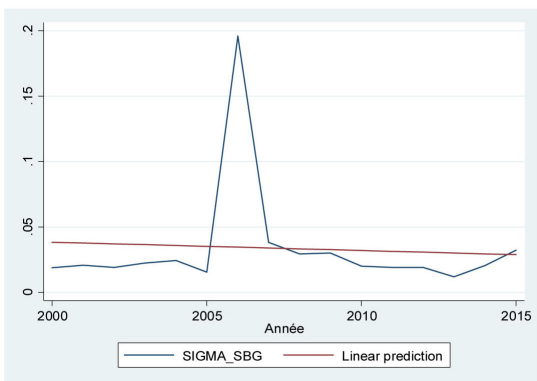

Debt/GDP ratio

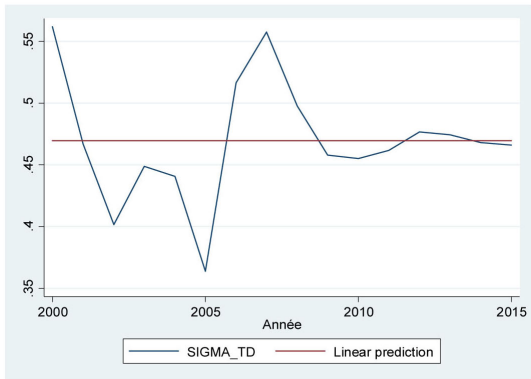

Payroll/Tax revenue

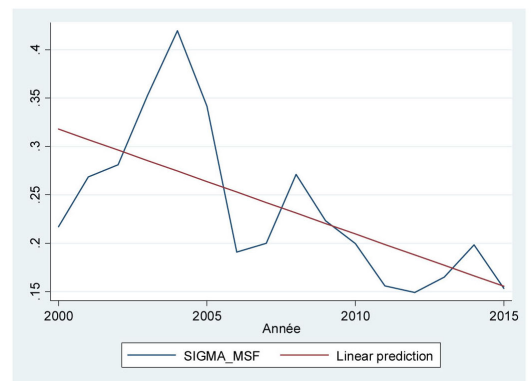

Graph 2. Representation of the dispersions of the convergence sigma WAEMU countries after the adoption of the debt rules. Source: Author.

Table 5. Results of the convergence of WAEMU countries after adoption of the debt rules.

\begin{tabular}{cccc}
\hline & Overall fiscal balance/GDP & Debt/GDP ratio & Payroll/Tax revenue \\
\hline \multirow{2}{*}{ Sigma } & -0.0006 & $1.63 \mathrm{e}-07$ & $-0.0108^{* * *}$ \\
& $(-0.26)$ & $(0.00)$ & $(-3.17)$ \\
\hline
\end{tabular}

Source: Author. $\left({ }^{* *}\right),\left({ }^{*}\right)$, and $\left({ }^{*}\right)$ respectively signify significance at the $1 \%, 5 \%$ and $10 \%$.

Overall, the results obtained in the context of the convergence sigma analysis (before and after the introduction of the debt rules) for the WAEMU countries are in line with those reported in the previous works (Wane, 2004; Boogardes \& Tsangarides, 2005; Bamba, 2004; Dore \& Masson, 2002; Houssa, 2006; Ndiaye, 2007; Diarra, 2016). In addition, it is apparent from the analysis of these authors that the WAEMU countries have experienced periods of both divergence and convergence.

Overall, there is a heterogeneity of WAEMU country behaviour in the convergence process. This state of affairs is explained by the structural variations. Indeed, economies react differently when they are affected by asymmetric shocks. Due to the fact that fiscal policy is the only stabilization instrument, it reflects the divergence of preferences in economic policy.

However, the phases of convergence (before the introduction of the rules) and divergence (after the introduction of the rules) at the level of the overall fiscal balance of the States are linked to asymmetric shocks affecting them, and to the structural heterogeneity that results in non-cooperative use of budget instruments.

With respect to other fiscal variables (debt to GDP, wage bill to tax revenue), the degrees and dynamics of convergence vary and hide a large disparity due to adverse movements in the economic cycle.

\section{Conclusion}

Respect for the Convergence Criteria, defined in the framework of the Convergence, Stability, Growth and Solidarity Pact, should be an important step in the process of reducing structural disparities between the EU Member States and 
fostering coordination between national fiscal policies and the common monetary policy. In addition, it is necessary to assess the impact of the financial structure of the EU economies on their responses to monetary shocks, which would eventually lead to a homogeneity and convergence of the responses of different economies to decisions of monetary policy. This approach would enhance the effectiveness of the BCEAO's monetary action, including its impact on integrated economic activity.

In the end, the analysis of the convergence sigma reveals a heterogeneity of WAEMU country behaviour in the convergence process. This state of affairs is explained by the structural differences. Indeed, economies react in various manners when they are affected by asymmetric shocks. Because fiscal policy is the only stabilization instrument, it reflects the divergence of preferences in economic policy. However, the phases of convergence (before the introduction of the rules) and divergence (after the introduction of the rules) at the level of the overall fiscal balance of the States are linked to the asymmetric shocks affecting them, and to the structural heterogeneity that seems to result in non-cooperative use of budget instruments.

In view of the widening of the WAEMU zone towards the West African Monetary Zone (WAMZ) or the ECOWAS zone, asymmetries are expected to amplify, a further reason why the problem of heterogeneity still raises important questions. Given this observation, this problem could be addressed in future studies by integrating the specificities of the WAMZ or ECOWAS.

\section{Conflicts of Interest}

The author declares no conflicts of interest regarding the publication of this paper.

\section{References}

Bamba, N. (2004). Analyse du Processus de Convergence dans la Zone UEMOA (p. 43). WIDER Research Paper, No. 2004/18. https://www.wider.unu.edu/sites/default/files/rp2004-018.pdf

Barro, R. (1991). Economic Growth in a Cross-Section of Countries. Quarterly Journal of Economics, 106, 407-444. https://doi.org/10.2307/2937943

Barro, R., \& Sala-i-Martin, X. (1992). Convergence. Journal of Political Economy (JPE), 100, 223-251. https://www.journals.uchicago.edu/doi/pdfplus/10.1086/261816

https://doi.org/10.1086/261816

Barro, R., \& Sala-i-Martin, X. (1995). Economic Growth. New York: McGraw-Hill, Inc.

Barthe, M. (2000). Economie de l'Union européenne. Paris: Economica.

Baumol, W. J. (1986). Productivity Growth, Convergence, and Welfare: What the Long-Run Data Show. The American Economic Review, 76, 1072-1085. http://www.jstor.org/stable/1816469

Bernard, A., \& Durlauf, S. (1991). Convergence of International Output Movements. NBER Working Paper, No. 3717. https://doi.org/10.3386/w3717

Boogardes, P., \& Tsangarides, C. (2005). Ten Years after the CFA Franc Devaluation: 
Progress towards Regional Integration in the WAEMU (p. 31). IMF Working Paper, WP/05/145. https://doi.org/10.5089/9781451861648.001

Canova, F., \& Marcel, A. (1995). The Poor Stay Poor: Non-Convergence across Country and Regions. CEPR Workshop on Empirical Macroeconomics. https://econ-papers.upf.edu/papers/137.pdf

De Long, J. B. (1988). Productivity Growth, Convergence, and Welfare: Comment. The American Economic Review, 78, 1138-1154. https://www.jstor.org/stable/1807174

Diarra, S. (2014). Dynamique de Convergence dans la Zone UEMOA: Du Pacte de 1999 aux Nouveaux Critères de 2015. Document de Réflexion, DR 2015.2.

Diarra, S. (2016). Analyse rétrospective du respect des nouveaux critères de convergence de l'UEMOA. Revue d'Économie du Développement, 24, 79-98. https://doi.org/10.3917/edd.301.0079

Dore, O., \& Masson, P. (2002). Experience with Budgetary Convergence in the WAEMU (p. 28). IMF Working Paper, WP/02/108. https://doi.org/10.5089/9781451853117.001

Fouda Owoundi, J. (2009). La convergence des politiques économiques dans la zone franc: Où en est-on 15 ans après? L'Actualité Économique, 85, 319-354. https://doi.org/10.7202/044880ar

Galor, O. (1996). Heterogeneity and Club Convergence in Growth Models. Providence, RI: Brown University.

Gaulier, G., Hurlin, C., \& Jean-Pierre, P. (1997). Conditionnal Convergence: Panel Data Approach. Communication à la 7̇me Conférence sur les données de Panel, Paris.

Guillaumont, S., \& Tapsoba, S. (2009). Procyclicité de la politique budgétaire et surveillance multilatérale dans les unions monétaires africaines (p. 46). CERDI, Etudes et Documents, E2009.04. https://halshs.archives-ouvertes.fr/halshs-00554337

Gupta, S., Powell, R., \& Yang, Y. (2005). The Macroeconomic Challenges of Scaling Up Aid to Africa. IMF Working Paper, WP/05/179.

https://doi.org/10.5089/9781451861983.001

Haldane, A. G.., \& Hall, S. G. (1991). Sterling's Relationship with the Dollar and the Deutschemark: 1976-89. The Economic Journal, 101, 436-443.

https://www.jstor.org/stable/2233550

Houssa, R. (2006). Monetary Union in West Africa and Asymmetric Shocks: A Dynamic Structural Factor Model Approach. Journal of Development Economics, 85, 319-347. https://doi.org/10.1016/j.jdeveco.2006.05.003

IMF (2013). Les politiques communes des pays membres de l'UEMOA. Washington DC: IMF.

Lucas, R. E. (1988). On the Mechanics of Economic Development. Journal of Monetary Economics, No. 22, 3-42. https://doi.org/10.1016/0304-3932(88)90168-7

Mankiw, M., Romer, D., \& Weil, D. (1992). A Contribution to the Empirics of Economic Growth. QJE, 107, 407-438. https://doi.org/10.2307/2118477

Ndiaye, M. (2007). Respect des critères de convergence versus harmonisationdes critères de convergence: Étude comparative des performances des indicateurs de convergence économique dans la zone Franc en Afrique (UEMOA et CEMAC). African Integration Review, 1, 31-69.

Ngoma, J. (2000). Analyse des chocs d'offre et de demande dans la zone CFA: Une methode structurelle d'autorégression vectorielle. CRDE, 13, 38.

Ondo, O., \& Bercart, A. (1997). Zone monétaire optimale et convergence dans les unions monétaires en Afrique. Congrès de Porto et Evora. 
Quah, D. (1993). Galton's Fallacy and Tests of Convergence Hypothesis. CEPR Discussion Paper, No. 820. https://doi.org/10.2307/3440905

Quah, D. (1996). Convergence Empirics across Countries with (Some) Capital Mobility. Journal of Economic Growth, 1, 95-124. https://doi.org/10.1007/BF00163344

Ramsey, F. (1928). A Mathematical Theory of Saving. Economic Journal, 38, 543-559. https://doi.org/10.2307/2224098

Romer, P. (1986). Increasing Return and Long-Run Growth. Journal of Political Economy (JPE), 94, 1002-1037. http://www.jstor.org/stable/1833190 https://doi.org/10.1086/261420

Sarr, M., \& N'diaye, C. (2010). (A)symétrie et convergence des politiques et chocs budgétaires en Zone UEMOA. Revue Economique et Monétaire (REM), 6-8, 9-46.

Solow, R. (1956). A Contribution to the Theory of Economic Growth. Quarterly Journal of Economics, 70, 65-94. https://doi.org/10.2307/1884513

Tanimoune, N., Combes, J.-L., \& Plane, P. (2005). Les effets non linéaires de la politique budgétaire: le cas de l'Union Economique Ouest Africaine. Etudes et Documents, CERDI, No. E 2005.20. http://publi.cerdi.org/ed/2005/2005.20.pdf

UEMOA (2016). Rapport semestriel d'exécution de la surveillance multilateral (p. 100). UEMOA Working Paper Commission.

UEMOA (2017). Rapport semestriel d'exécution de la surveillance multilateral (p. 100). UEMOA Working Paper.

Wane, A. (2004). Growth and Convergence in WAEMU Countries (p. 36). IMF Working Paper, WP/04/198. 


\section{Annex 1: Results of the Estimation of the Convergence WAEMU Countries before the Adoption of the Debt Rules}

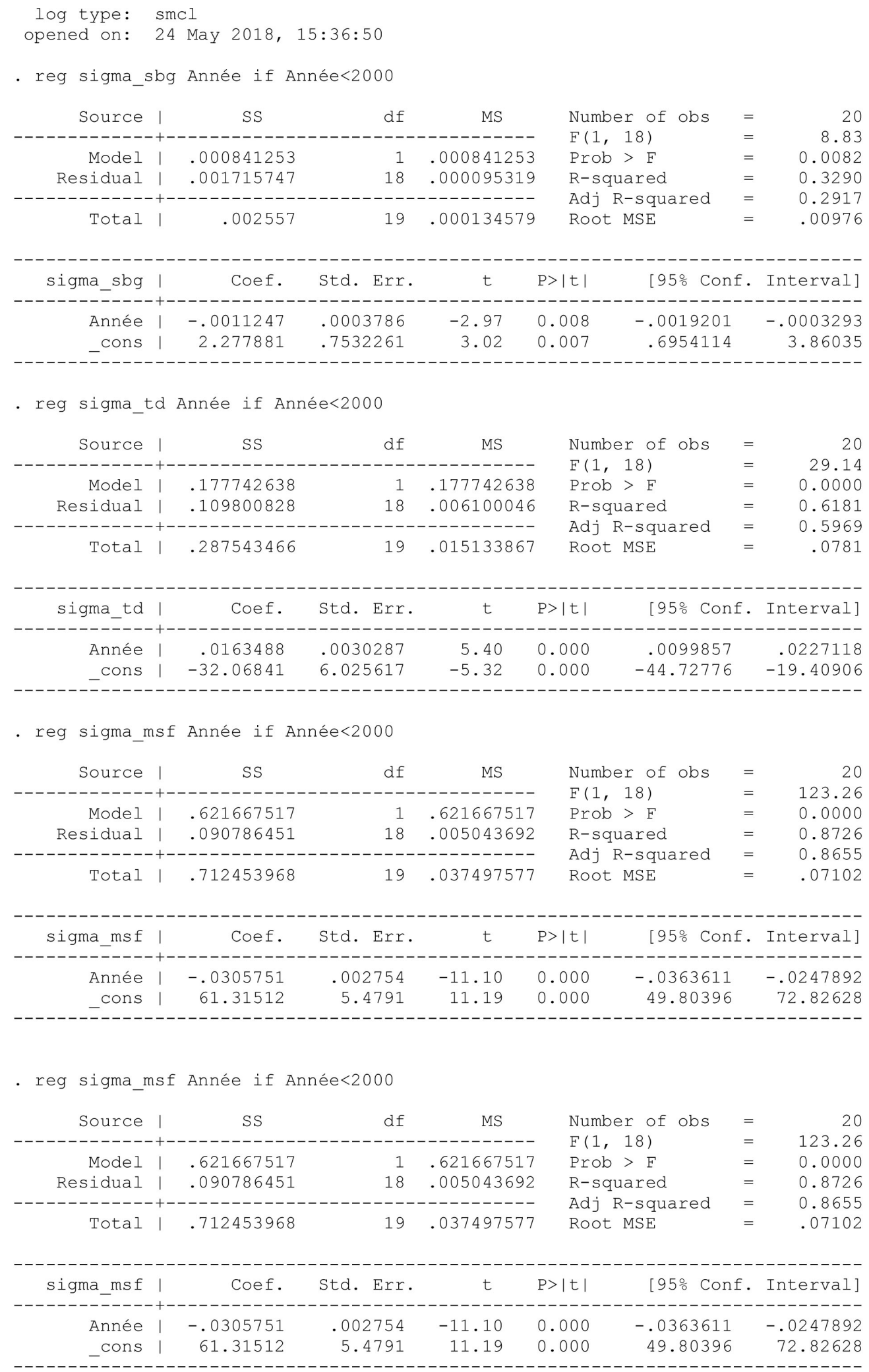




\section{Annex 2: Results of the Estimation of the Convergence WAEMU Countries after the Adoption of the Debt Rules}

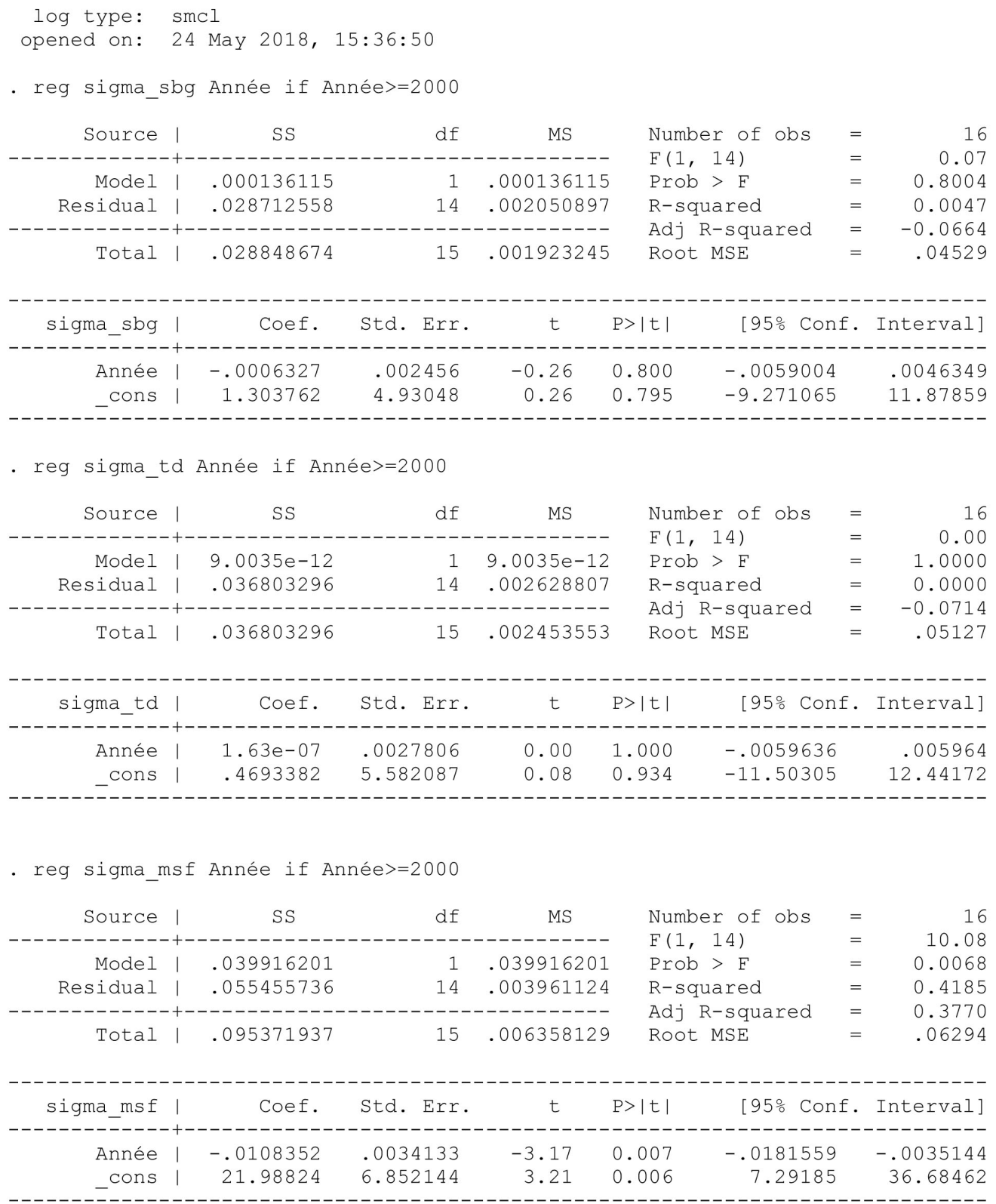

